\title{
Strength and Durability of Mortar Made with Plastics Bag Waste (MPBW)
}

\author{
Youcef Ghernouti $^{1), *}$, and Bahia Rabehi ${ }^{2)}$
}

(Received April 19, 2012, Revised July 23, 2012, Accepted August 1, 2012, Published online September 18, 2012)

\begin{abstract}
The aim of this study is to explore the possibility of re-cycling a waste material that is now produced in large quantities, while achieving an improvement of the mechanical properties and durability of the mortar. This study examines the mechanical properties and the durability parameters of mortars incorporating plastics bag wastes (PBW) as fine aggregate by substitution of a variable percentage of sand (10, 20, 30 and $40 \%)$. The influence of the PBW on the, compressive and flexural strength, drying shrinkage, fire resistance, sulfuric acid attack and chloride diffusion coefficient of the different mortars, has been investigated and analyzed in comparison to the control mortar. The results showed that the use of PBW enabled to reduce by 18-23\% the compressive strength of mortars containing 10 and $20 \%$ of waste respectively, which remains always close to the reference mortar (made without waste). The replacement of sand by PBW in mortar slows down the penetration of chloride ions, improves the behavior of mortars in acidic medium and improves the sensitivity to cracking. The results of this investigation consolidate the idea of the use of PBW in the field of construction.
\end{abstract}

Keywords: waste, plastics bag, mortar, strength, valorization, durability.

\section{Introduction}

The valorization of waste in civil engineering is an important sector to the extent that the products to be obtained are not subjected to rigorous quality standards too. The valorization of waste affects two major impacts, environmental impact is solved by disposing of such waste and the economic impact is the use of that in industry or in the field of construction, this waste has the advantage of being available large quantity and low value (Chanvillard and Aitcin 1990; Hassani et al. 2005). The cementing materials, by their performance in terms of mechanical strength and durability dominate the market of construction materials.

The addition of polymeric waste to concrete corresponds to a new perspective in research activities, integrating the areas of concrete technology and environmental technology.

Industrial and domestic waste has a significant percentage of polymeric materials in its constitution, which occupies a considerable volume on landfills. Therefore its recycling is

\footnotetext{
${ }^{1)}$ LSTE, Laboratoire des Sciences et Techniques de l'Eau, University of Mascara, Mascara, Algeria.

*Corresponding Author; E-mail: y_ghernouti@yahoo.fr

${ }^{2)}$ UR/MPE, Unité de Recherche: Matériaux, Procédés et Environnement, Université of Boumerdes, Boumerdes, Alegria.

Copyright $($ The Author(s) 2012. This article is published with open access at Springerlink.com
}

interesting to research and development of technologies for minimizing the problems caused by this waste.

Polypropylene (Mesbah and Buyle-Bodin 2008), polyethylene (Zoorob and Suparma 2000) and nylon (Song et al. 2005), besides other materials (Sivakumar and Santhanam 1995; Ogi et al. 2005) are examples of polymeric additions to concrete, mainly in the fiber shape, providing the reinforcement of concrete structures, known as "fiber-reinforced concrete".

Different studies, as of Rebeiz (2007), Choi et al. (2005) and Jo et al. (2007), have analyzed the effect of addition of recycled PET to the properties of concrete. The fibers of recycled $\mathrm{PET}$ easily mix in the concrete, giving new properties to the material (Ochi et al. 2007). Khaloo et al. (2008) have observed that the addition of tire rubber particles provided the concrete with higher ductility in compressive strength testing, if compared with concrete without addition.

One of the advantages of the use of recycled plastic in concrete is the reduction of solid waste in landfills (Siddique et al. 2008).

The present study focused on the use of plastic aggregates resulting from the crushing of plastic bags waste rejected into nature and to find new ways of valorization in the field of construction. We will present, therefore, compressive and flexural strength of mortars. Their durability towards the chemical attacks such as the acids and the diffusion of chlorides ions. After that, shrinkage tests prevented with the ring and the follow-up of induced cracking will bring relevant elements making it possible to appreciate the resistance of samples to the cracking of withdrawal. 


\section{Experimental Program}

\subsection{Materials}

\subsubsection{Cement}

Cement used is a CEM II 32.5 from Algeria with real compressive strength of $45 \mathrm{MPa}$. Mineralogical and chemical compositions of cement are listed in Table 1.

The physical and rheological properties of cement are listed in Table 2.

\subsubsection{Aggregates}

The aggregates used in this investigation are sand obtained from local sources and the plastic waste resulting from crushing of rejected plastic bags; its physical properties are listed in Table 3.

Particle size analysis of sand and the plastic waste is represented in Fig. 1.

Waste of the plastic bags is obtained according to the following technological chain (Fig. 2).

\subsection{Formulation of Mortars}

We will use normal mortars, according to standard (NFP 15-403), the composition is the following one: $450 \mathrm{~g}$ of cement, $225 \mathrm{ml}$ of water and 1,350 $\mathrm{g}$ of sand.

This is corresponding to a ratio sands/cement equal to 3 . The rate of mixing water is maintained constant for the whole of batches $\mathrm{W} / \mathrm{C}=0.5$. The normal mortar describes previously is produced using a mixer HOBART, in a tank of five liters spreading with the characteristics of standard NFP 15-411. The plastic waste was introduced by substitution of a variable percentage of sand such as: 10, 20, 30 and $40 \%$ and that, to better see their influence on the mechanical physic properties as well as behavior of these mortars with

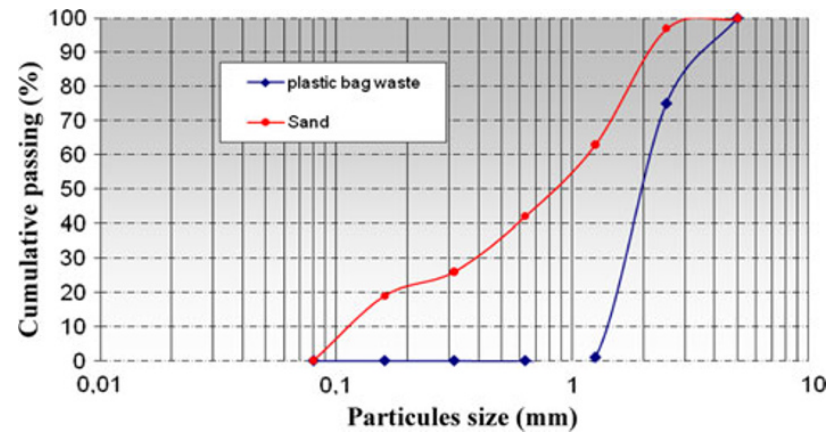

Fig. 1 Granular size analysis of sand and waste.

towards the chemical attacks. The different compositions of mortars studied and their notations are presented in Table 4.

\section{Results and Discussion}

\subsection{Mechanical Strength}

The flexural and compressive strength are tested at 7, 28 and 90 days on prismatic specimens $(4 \times 4 \times 16) \mathrm{cm}^{3}$. Each mechanical property value presented in the following of the article is the average value obtained from tests performed on three specimens. The evolution of the compressive and flexural strength of mortars are represented in Figs. 3 and 4.

We notice the continuous increase of the flexural and compressive strength for the various mortars according to the ages $(14,28$, and 60 days). This increase is due to the hydration of cement during time what causes the evolution of compactness. We notices also a reduction in the mechanical strength according to the increase in percentage of plastic waste in the mortars, but remains always close with this last for the case to the percentages 10 and $20 \%$

Table 1 Chemical and mineralogical composition of cement.

\begin{tabular}{c|c|c|c|c|c|c|c|c|c|c|c|c}
\hline \multicolumn{9}{c|}{ Chemical composition } & \multicolumn{5}{c}{ Mineralogical composition } \\
\hline $\mathrm{CaO}$ & $\mathrm{SiO}_{2}$ & $\mathrm{Al}_{2} \mathrm{O}_{3}$ & $\mathrm{Fe}_{2} \mathrm{O}_{3}$ & $\mathrm{MgO}$ & $\mathrm{SO}_{3}$ & $\mathrm{I}$. loss QQ & $\mathrm{Na}_{2} \mathrm{O}$ & $\mathrm{K}_{2} \mathrm{O}$ & $\mathrm{C}_{3} \mathrm{~S}$ & $\mathrm{C}_{2} \mathrm{~S}$ & $\mathrm{C}_{3} \mathrm{~A}$ & $\mathrm{C}_{4} \mathrm{AF}$ \\
\hline \hline 58.43 & 22.97 & 5.76 & 4.36 & 2.03 & 2.64 & 6.49 & 0.35 & 0.76 & 53 & 27 & 5 & 13 \\
\hline
\end{tabular}

Table 2 Physical properties of cement.

\begin{tabular}{c|c}
\hline Density, $\mathrm{D}\left(\mathrm{g} / \mathrm{cm}^{3}\right)$ & 3.1 \\
\hline Specific surface Blaine SSB $\left(\mathrm{cm}^{2} / \mathrm{g}\right)$ & 3510 \\
\hline The normal consistency NC $(\%)$ & 25 \\
\hline The initial setting time IST (min) & 155 \\
\hline The final setting time FST (min) & 212 \\
\hline
\end{tabular}

Table 3 Physical properties of sand and plastic waste.

\begin{tabular}{c|c|c}
\hline & Sand & Plastic waste \\
\hline \hline The apparent density, $\mathrm{Ad}\left(\mathrm{g} / \mathrm{cm}^{3}\right)$ & 1.45 & 0.53 \\
\hline Specific gravity, SG $\left(\mathrm{g} / \mathrm{cm}^{3}\right)$ & 2.56 & 0.87 \\
\hline Visual equivalent, VES (\%) & 80 & - \\
\hline Finesse modulus, Fm & 2.5 & 4.7 \\
\hline
\end{tabular}



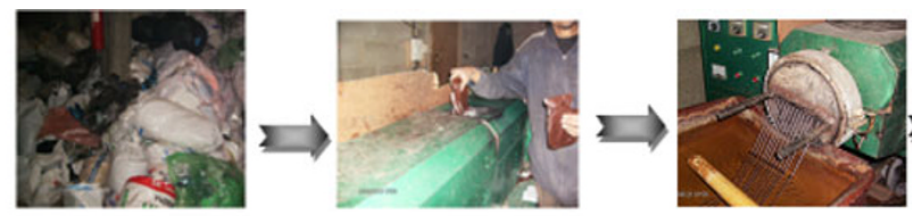

2. Heat treatment

3. Cooling

1. Recovery of the plastic bags
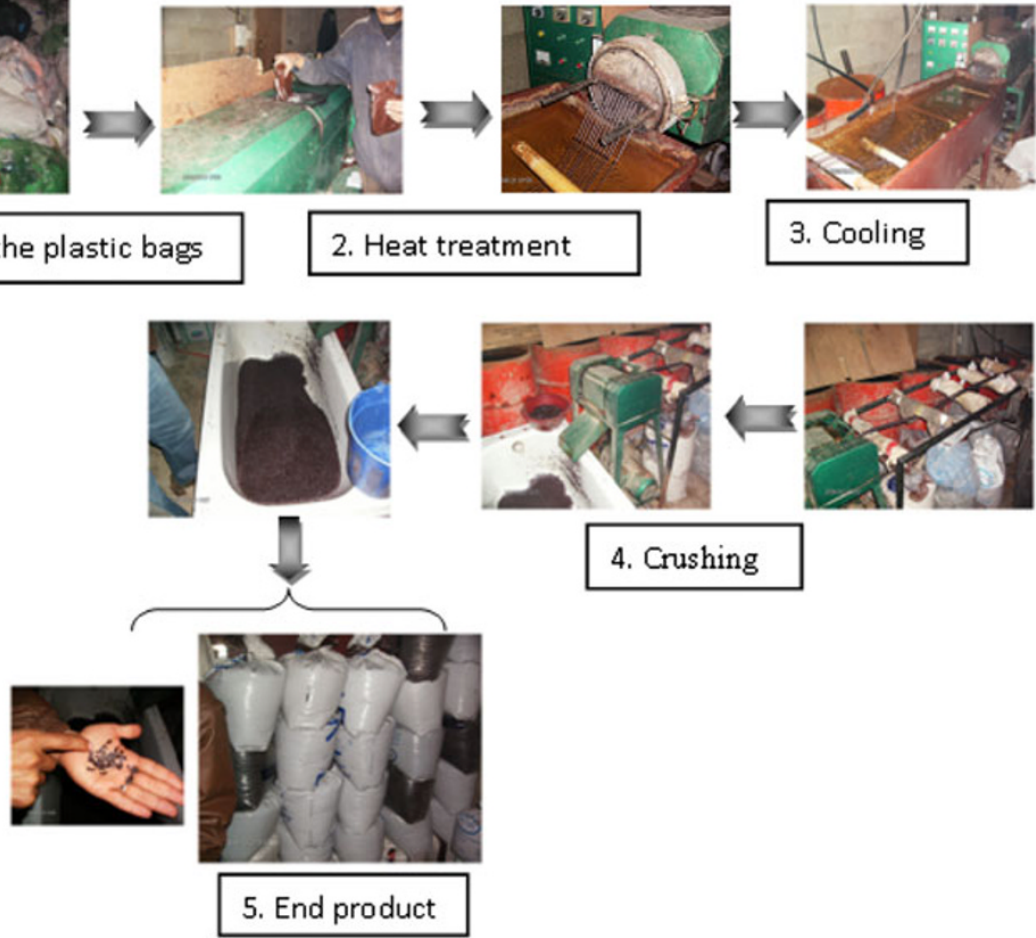

Fig. 2 Stages of obtaining waste of the plastic bags.

Table 4 Mix proportions of the mortars $\left(\mathrm{kg} / \mathrm{m}^{3}\right)$.

\begin{tabular}{|c|c|c|c|c|c|}
\hline Notation & Description & Cement & Water & Sand & Plastic waste \\
\hline MR & Reference mortar & 586 & 293 & 1,758 & 0 \\
\hline MP10 & $\begin{array}{c}\text { Mortar with } 10 \% \\
\text { plastic waste }\end{array}$ & 586 & 293 & 1,582 & 61 \\
\hline MP20 & $\begin{array}{c}\text { Mortar with } 20 \% \\
\text { plastic waste }\end{array}$ & 586 & 293 & 1,406 & 122 \\
\hline MP30 & $\begin{array}{c}\text { Mortar with } 30 \% \\
\text { plastic waste }\end{array}$ & 586 & 293 & 1,230 & 183 \\
\hline MP40 & $\begin{array}{c}\text { Mortar with } 40 \% \\
\text { plastic waste }\end{array}$ & 586 & 293 & 1,055 & 244 \\
\hline
\end{tabular}

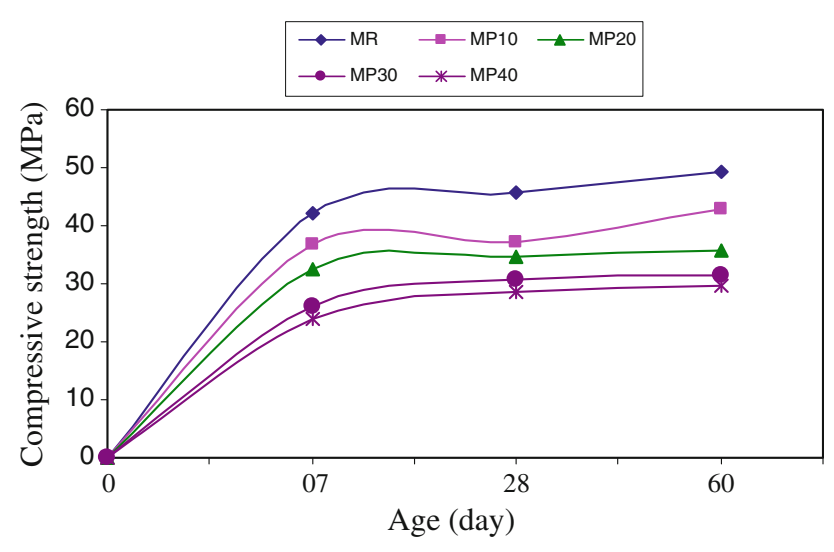

Fig. 3 Compressive strength of mortars.

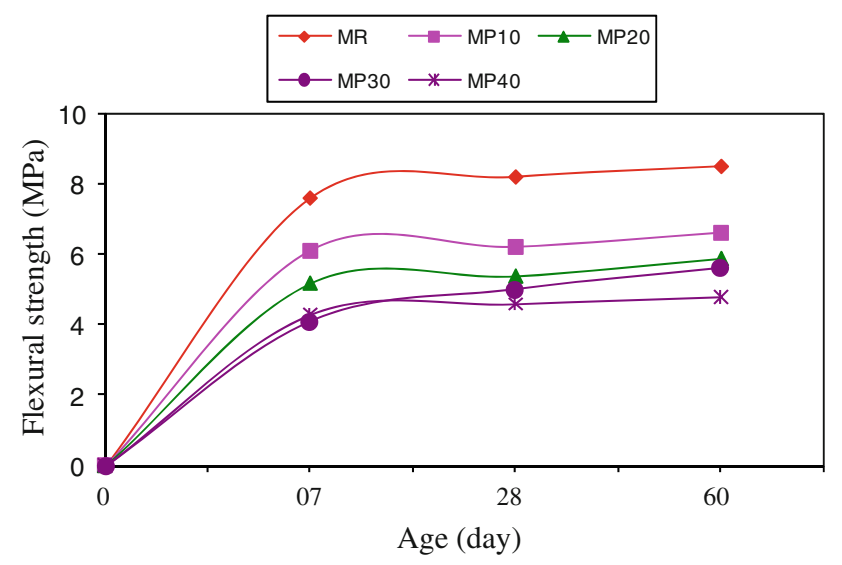

Fig. 4 Flexural strength of mortars. 
when we recorded a fall of compressive strength at 28 days of about 18 and $23 \%$ respectively.

This fall of strength must mainly with:

- The substitution of the sand by waste which is less resistant.

- Low roughness of waste which returns adherence between the grains and cement paste.

\subsection{Behaviour of Mortars in the Acid Medium}

For the characterization of chemical resistance with respect to the acids environment the mortars were run in prismatic moulds $(4 \times 4 \times 16) \mathrm{cm}^{3}$. After $24 \mathrm{~h}$, the samples were unmoulded and preserved in water. After 28 days of cure, the samples are immersed in a solution of $5 \%$ of strong sulfuric acid $\left(\mathrm{H}_{2} \mathrm{SO}_{4}\right)$. The variation of the weight of samples is examined at different age. The chemical solution is renewed every 7 days. At the day of the test the parts of mortar having undergoes a visible degradation are cleaned carefully with water, thereafter the samples are dried during half an hour with the free air (ASTM C 267-96), the chemical resistance in acid medium is evaluated by the measurement of the loss of weight of specimens.

After immersion of different mortars in sulfuric acid solution $\left(5 \% \mathrm{H}_{2} \mathrm{SO}_{4}\right)$, visual degradation appear in these samples. Figure 5 shows the state of specimens after 60 days

The follow-up of the loss of weight of various mortars immersed in a sulfuric acid solution $\left(5 \% \mathrm{H}_{2} \mathrm{SO}_{4}\right)$ show a continuous loss of weight during time. This loss is due to the deposit of the gypsum, which is formed following the reaction between the portlandite and sulfuric acid according to the chemical reaction:

$$
\mathrm{Ca}(\mathrm{OH})_{2}+\mathrm{H}_{2} \mathrm{SO}_{4} \rightarrow \mathrm{CaSO}_{4}+2 \mathrm{H}_{2} \mathrm{O}
$$

The gypsum deposited is then washed, which gives us a solution. The visual examination of the samples shows that the mortars with addition of plastic waste keep their form after immersion in the acid, the loss of weight decreases according to the increase of the waste percentage. What indicates the good behavior of these mortars towards the acid medium (Rossignolo and Agnesini 2004; Monteny et al. 2001).

\subsection{Penetration of Chloride lons}

The penetration resistance of the ions chloride in the mortar and the concrete is one of the most important questions concerning the durability of the concrete structures. When the chloride concentration exceeds a certain threshold, a depassivation of steel occurs and there is a beginning of corrosion for reinforced steel (Thomas 1996; Alonso et al. 2000). Consequently, the development of protection materials with a penetration resistance of chloride is required for the concrete structures.

For the tests we used cubic specimens $(10 \times 10 \times 10) \mathrm{cm}^{3}$. The mortars were made in accordance with the standard EN 196. Then the specimens are introduced into a concentrated $\mathrm{NaCl}$ solution with $5 \%$. To evaluate the durability of the mortars from the penetration of the ions chlorides, we followed the evolution penetration depth of the ions chlorides to 28 and 60 days. The solutions were changed every 7 days and this until the old of 28 days, then every 28 days until the old of 60 days. To each test the sample will be devised in two parts, then we pours on each section a solution of $\mathrm{AgNO}_{3}$ according to the standard UNI 79287 (UNI 1978).

Figure 6 represents the value of penetration of the chlorides ions in different mortar according to the age of immersion in the solution from $(5 \% \mathrm{NaCl})$.

It is noticed that depth penetration of the chlorides ions for various mortars, increases with the time of immersion, and depth penetration of mortars with addition of plastic waste is low that of reference mortar because the plastic is a polymer and the polymers slow down the action of the chlorides ions (Ohaman 1987; Benosman et al. 2008).

\subsection{Restrained Shrinkage Test (Ring Test)}

To measure the restrained shrinkage, the principle is to coat a rigid ring made of steel with a mortar and given the expiry and nature of the cracking of an annular samples run around this steel heart, which must be sufficiently rigid to prevent the deformation of shrinking of material. Thus tensile stresses are developing in the material which fissures if its strength in traction is exceeded (Sandra 2003; Ahmed and Mihashi 2009; Hossain and Weiss 2004; Turcry et al. 2006; See et al. 2003). The mortars were made with the regulations of the standard EN 196-1. After hardening, the sample is

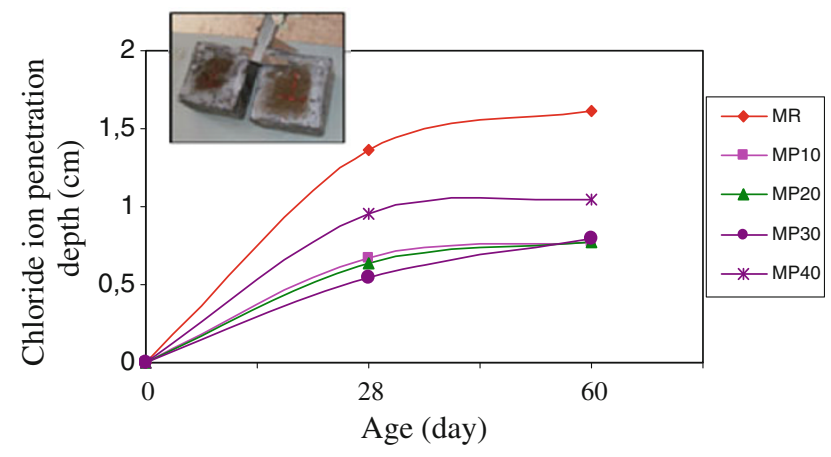

Fig. 6 Chloride ion penetration depth of mortars.

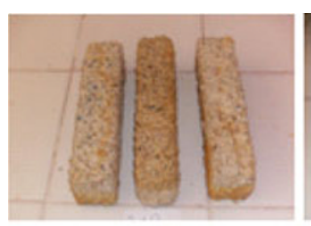

MR

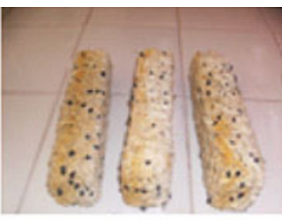

MP10

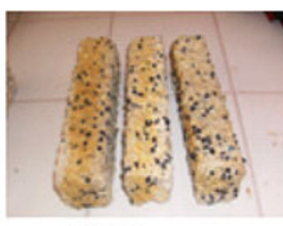

MP20

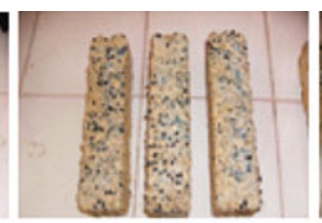

MP30

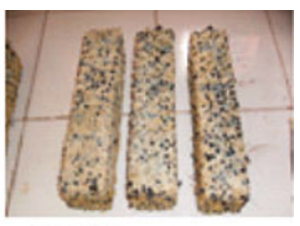

MP40

Fig. 5 State of the simples after 60 days immersion in $5 \% \mathrm{H}_{2} \mathrm{SO}_{4}$. 
subjected to the conditions wished to evaluate the effect of prevented withdrawal.

This test consists in determining the expiry and the nature cracking in annular samples of mortar containing waste, run around a sufficiently rigid steel heart to prevent the deformation. For the not availability of the rings we studied only the following compositions: MR, MP10, MP20 and MP30. The photographs of Table 5 represent the state of the cracking observed on the rings of the various mortars subjected to the prevented withdrawal at the 28 days age.

The mortar without addition presents two important and frank cracks on all the height of the annular simples, while for the mortars with addition of plastic waste we observed a less sensitivity to cracking by the appearance of less important cracks. The ring of mortar with addition of $20 \%$ of waste does not present any crack. For the rings with 10 and $30 \%$ of waste,

Table 5 Illustration of the cracking of mortars under drying shrinkage test.

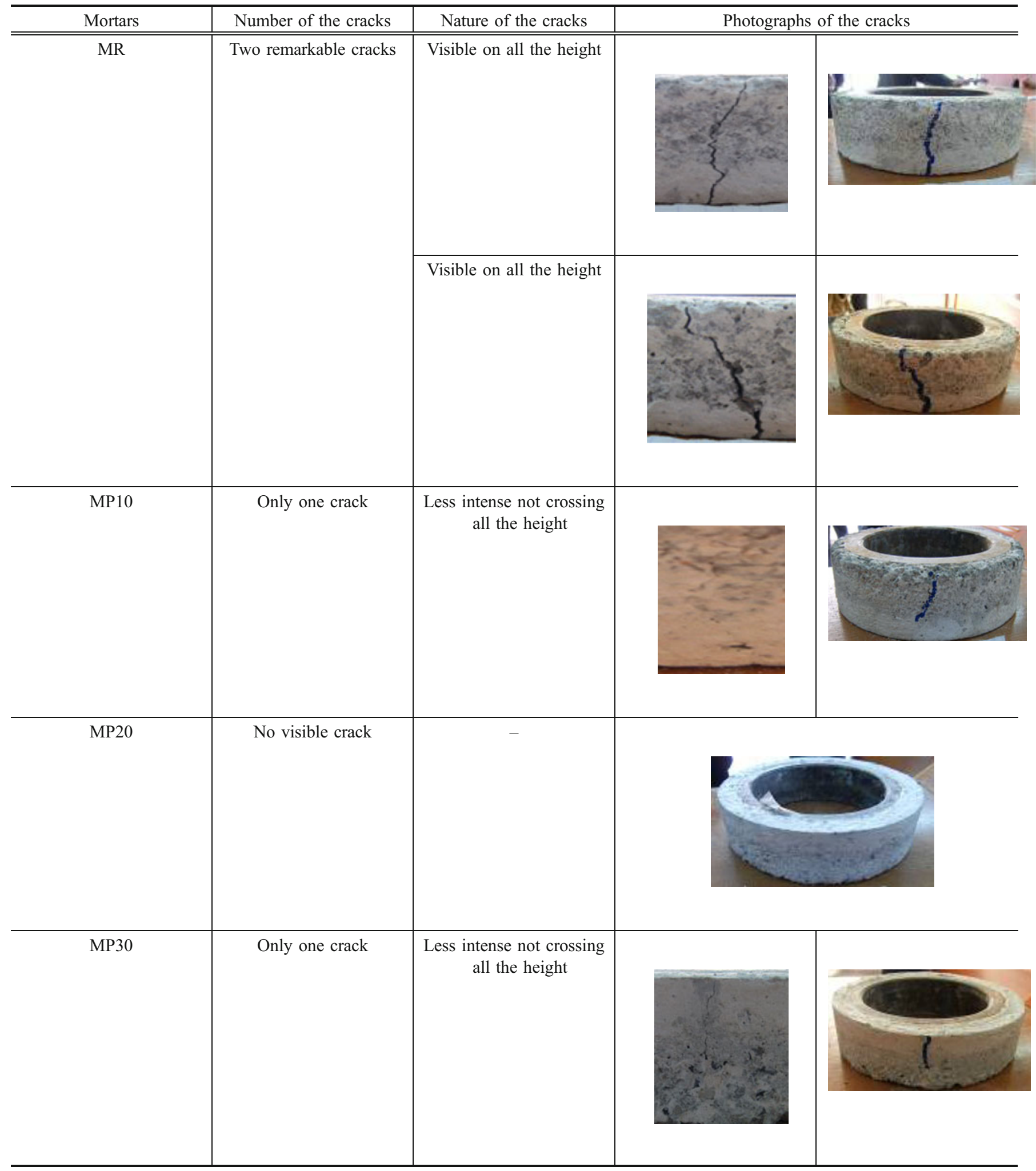



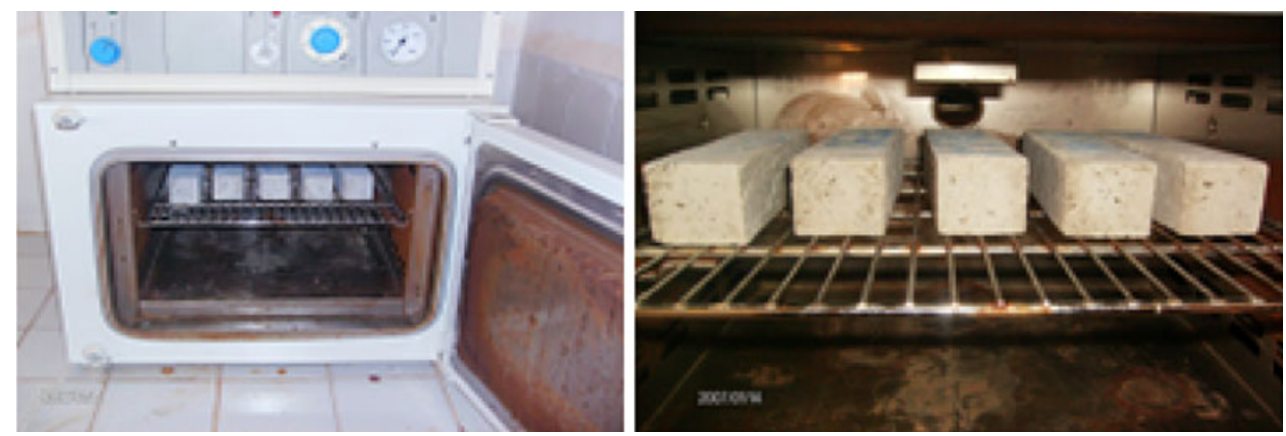

Fig. 7 Heat treatment of the mortars.

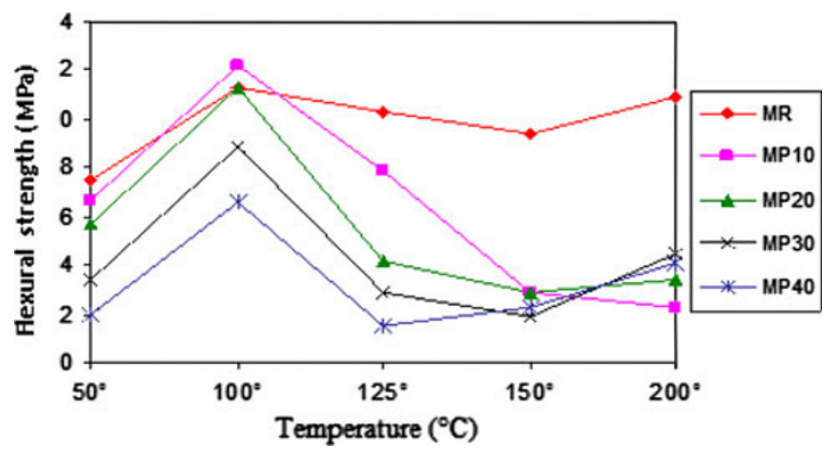

Fig. 8 Flexural strength of different mortars under various temperatures.

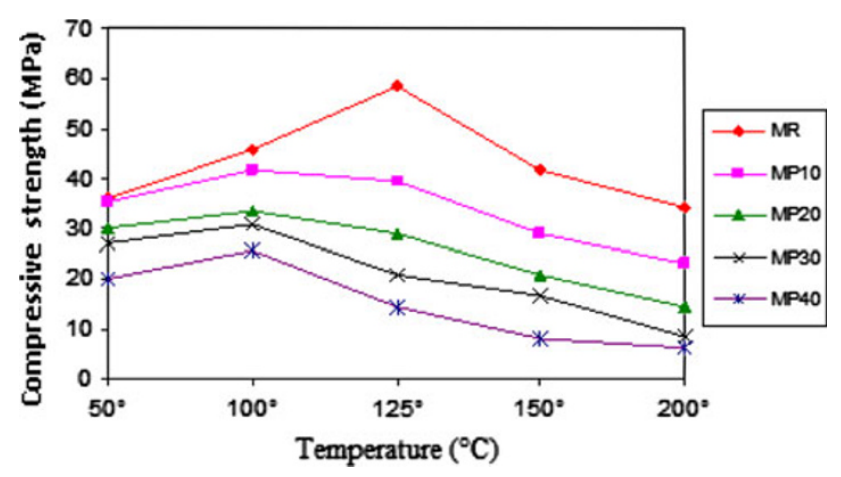

Fig. 9 Compressive strength of different mortars under various temperatures. we recorded a single crack which does not cross all the height of the body of test but its opening is less intense, which explains the beneficial effect of the plastic waste opposite the sensitivity to cracking of the mortars.

\subsection{Temperature Effect}

In order to see the performances of our specimens, elaborated with various percentages of waste, in height temperature, visual examination and mechanical tests of compressive and flexural strength were carried out for mortar $(4 \times 4 \times 16)$ $\mathrm{cm}^{3}$, preserved 28 days in water and drying ovens during $24 \mathrm{~h}$ under a fixed temperature $\left(50,100,125,150\right.$ and $\left.200{ }^{\circ} \mathrm{C}\right)$ (Fig. 7).

The results of compressive and flexural strength tests as well as the visual examination of the specimens are given as follows (Figs. 8, 9, 10, 11, 12, 13).

After crushing of specimens exposed to different thermal treatment, we notice an increase in strength in both temperature 50 and $125{ }^{\circ} \mathrm{C}$, for the reference mortar due to the beneficial role of temperature in the acceleration of hydration reactions. For the other temperatures a decrease of mechanical strength is recorded. For the mortars with plastic bag waste (PBW), we notice an increase in resistance between 50 and $100{ }^{\circ} \mathrm{C}$, this increase can be explained by the different dilation coefficient from the components of the mortar (sand and waste) which gives internal stresses, part of these constraints contributes to the equilibrium of the load and the other part participate in the rupture of the specimens (Barthélèmy and Kruppa 1978).
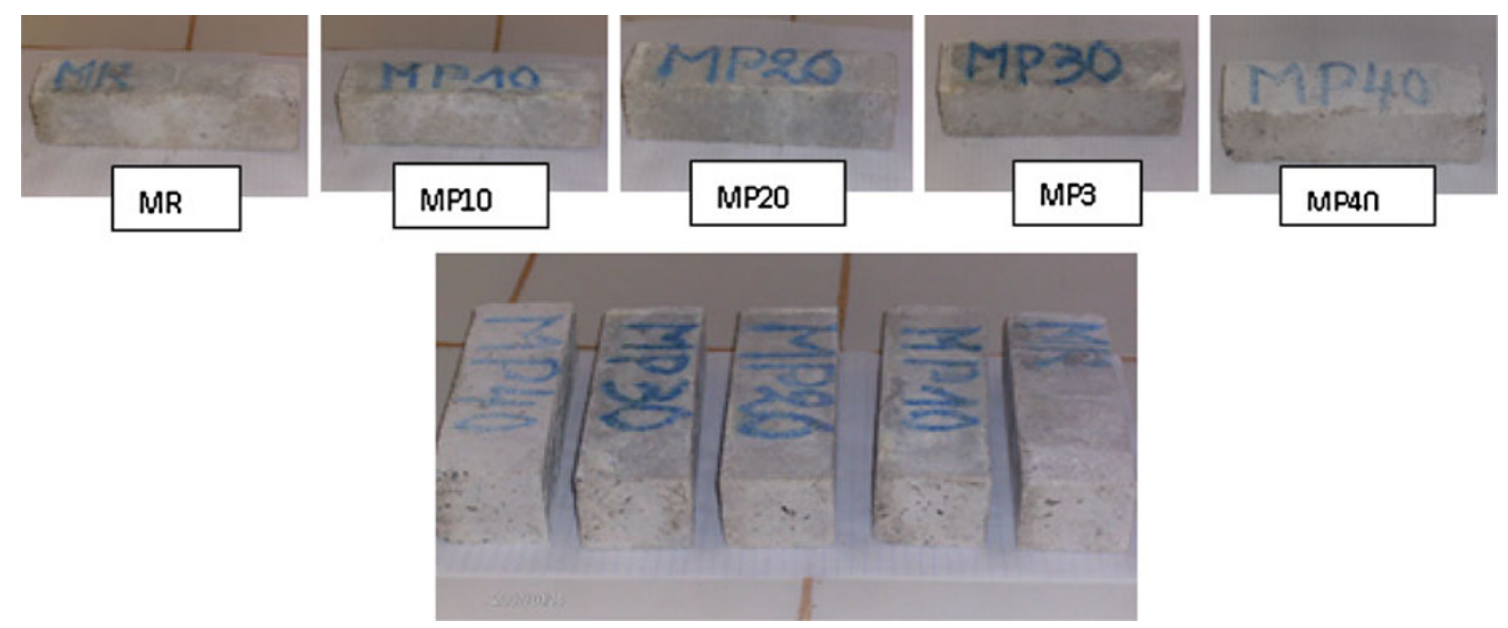

Fig. 10 Specimens after thermal treatment at 50 and $100{ }^{\circ} \mathrm{C}$. 

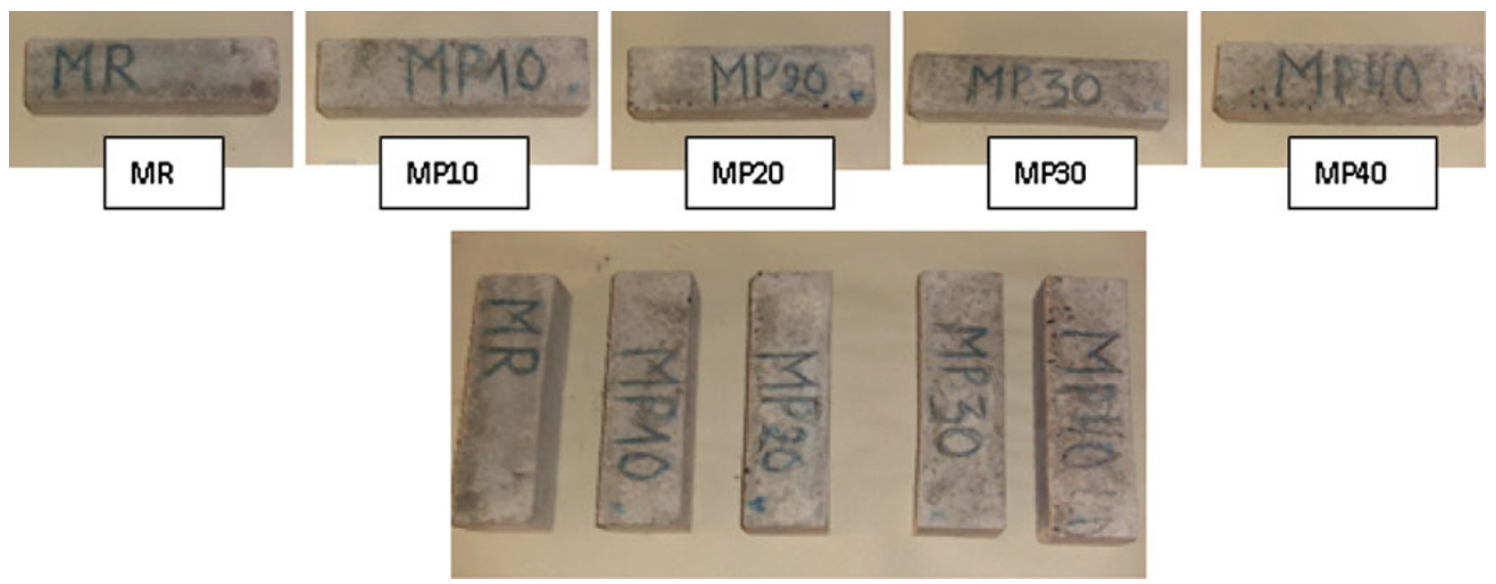

Fig. 11 Specimens after thermal treatment at $125^{\circ} \mathrm{C}$.
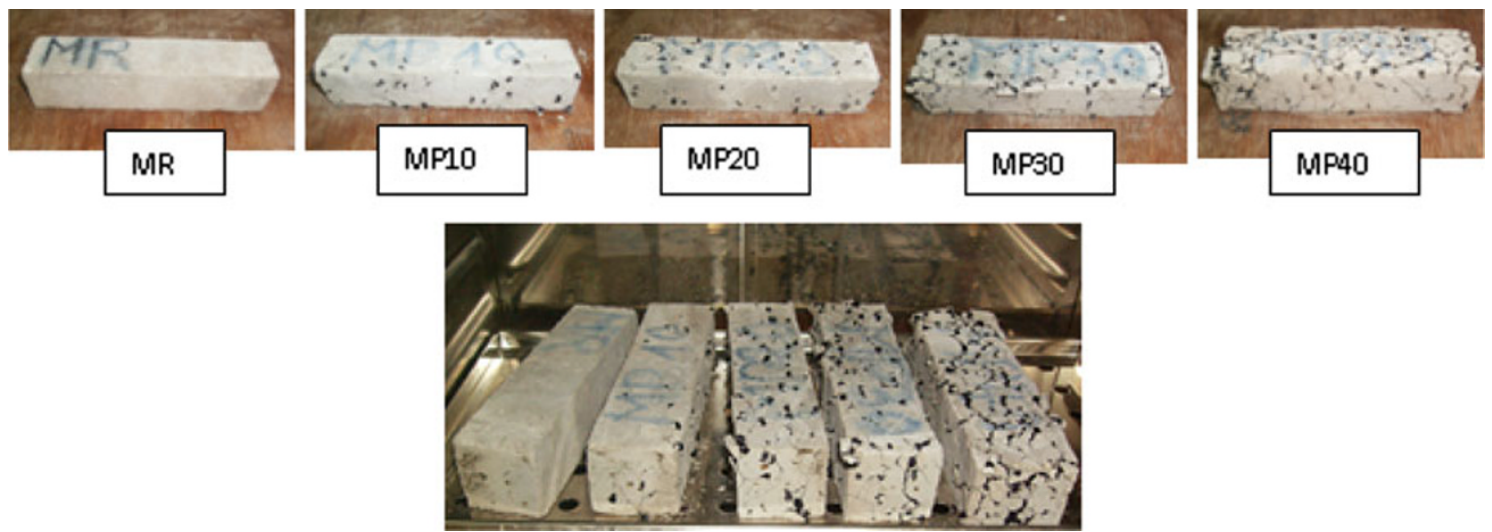

Fig. 12 Specimens after thermal treatment at $150{ }^{\circ} \mathrm{C}$.
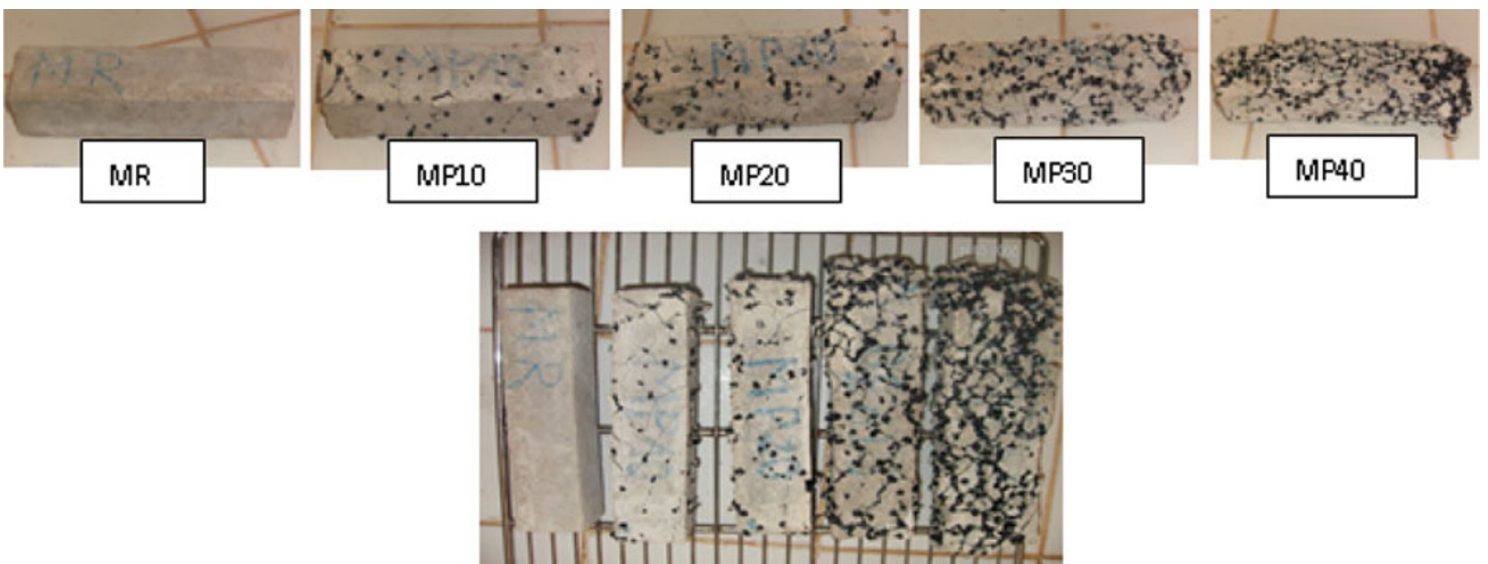

Fig. 13 Specimens after thermal treatment at $200{ }^{\circ} \mathrm{C}$.

It should be noted that strength decrease with the plastic addition, this is explained by the fact that the plastic is strongly influenced by the temperature.

The visual examination shows that all the samples of mortar containing waste preserved their initial states after thermal treatment at $125^{\circ} \mathrm{C}$, but they has start to become deformed and lose their aspect from $150{ }^{\circ} \mathrm{C}$.

\section{Conclusion}

This study investigates the valorization of PBW in field of construction. The effects of an incorporation of this waste on the physic mechanical properties of the mortars and their durability have been analyzed.

The following main conclusions can be drawn:

- A reduction in the mechanical resistance according to the increase in percentage of PBW, which remains always close to the mortar of reference, when we recorded a fall of compressive strength at 28 days about 18 and $23 \%$ for the mortars containing 10 and $20 \%$ of waste respectively.

- The loss of weight for the mortars preserved in the sulfuric acid, decreases according to the increase in the percentage of waste. What indicates the good behavior of these mortars in this medium. 
- The incorporation of PBW in the mortar slows down the penetration of ions chloride.

- Plastic waste improves the sensitivity to cracking of the mortar when it is subjected to the prevented withdrawal. The cracking of withdrawal appears in the form of a network of cracks shorter, not very open. In all the cases when resistance to the imposed deformations is a priority, this property is an asset for the durability of the structures.

- The mortars containing plastic waste, have a good behavior when it is subjected to the temperature effect, it preserved their initial states after thermal treatment at $125^{\circ} \mathrm{C}$.

Finally, PBW aggregates can be used successfully to replace conventional aggregates in mortar and concrete without any long term detrimental effects and with acceptable strength development properties.

\section{Acknowledgments}

This study was supported by the National Agency for Development and Research of Algeria.

\section{Open Access}

This article is distributed under the terms of the Creative Commons Attribution License which permits any use, distribution, and reproduction in any medium, provided the original author(s) and the source are credited.

\section{References}

Ahmed, S. F. U., \& Mihashi, H. (2009). Restrained shrinkageinduced cracking of light weight high performance fiber reinforced cementitious composites. American Journal of Engineering and Applied Sciences, 2(4), 775-780.

Alonso, C., Andrade, C., Castellote, M., \& Castro, P. (2000). Chloride threshold values to depassivate reinforcing bars embedded in a standardized OPC mortar. Cement and Concrete Research, 30(7), 1047-1055.

Barthélèmy, B., \& Kruppa, J. (1978). Résistance au feu des structures béton-acier-bois. Editions Eyrolles.

Benosman, A. S., Taibi, H., Mouli, M., Belbachir, M., \& Senhadji, Y. (2008). Diffusion of chloride ions in polymermortar composites (PET). Journal of Applied Polymer Science, 110(3), 1600-1605.

Chanvillard, G., \& Aitcin, P. C. (1990). Thin bonded overlays of fiber-reinforced concrete as a method of rehabilitation of concrete roads. Canadian Journal of Civil Engineering, 17(4), 521-527.

Choi, Y.-W., Moon, D.-J., Chung, J.-S., \& Cho, S.-K. (2005). Effects of waste PET bottles aggregate on the properties of concrete. Cement and Concrete Research, 35, 776781 .
Hassani, A., Ganjidoust, H., \& Maghanaki, A. A. (2005). Use of plastic waste (poly-ethylene terephthalate) in asphalt concrete mixture as aggregate replacement. Waste Management \& Research, 23, 322-327.

Hossain, A. B., \& Weiss, J. (2004). Assessing residual stress development and stress relaxation in restrained concrete ring specimens. Cement and Concrete Composites, 26, 531-540.

Jo, B., Tae, G., \& Kim, C. (2007). Uniaxial creep behavior and prediction of recycled-PET polymer concrete. Construction and Building Materials, 21, 1552-1559.

Khaloo, A., Dehestani, M., \& Rahmatabadi, P. (2008). Mechanical properties of concrete containing a high volume of tirerubber particles. Waste Management, 28, 2472-2482.

Mesbah, H. A., \& Buyle-Bodin, F. (2008). Efficiency of polypropylene and metallic fibres on control of shrinkage and cracking of recycled aggregate mortars. Construction and Building Materials, 13, 439-447.

Monteny, J., De Belie, N., Vincke, E., Verstraete, W., \& Taerwe, L. (2001). Chemical and microbiological tests to simulate sulfuric acid corrosion of polymer-modified concrete. Cement and Concrete Research, 31, 1359-1365.

Ochi, T., Okubo, S., \& Fukui, K. (2007). Development of recycled PET fiber and its application as concrete-reinforcing fiber. Cement and Concrete Composites, 29, 448-455.

Ogi, K., Shinodab, T., \& Mizuic, M. (2005). Strength in concrete reinforced with recycled CFRP pieces. Composites Part A: Applied Science and Manufacturing, 36, 893-902.

Ohaman, Y. (1987). Resistance of polymer-modified mortars to chloride penetration. Proceedings of the 4th International Conference on Durability of Building Materials \& Components, Singapore 4-6 Nov 1987 (pp. 559-566).

Rebeiz, K. S. (2007). Time-temperature properties of polymer concrete using recycled PET. Cement and Concrete Composites, 17, 603-608.

Rossignolo, J. A., \& Agnesini, M. V. C. (2004). Durability of polymer-modified lightweight aggregate concrete. Cement and Concrete Composites, 26, 375-380.

Sandra, B. (2003). Effet de l'incorporation des granulats caoutchouc sur la résistance à la fissuration des mortiers XXIemes rencontres universitaires de génie civil. Prix Rene Houpert.

See, H. T., Attiogbe, E. K., \& Miltenberger, M. A. (2003). Shrinkage cracking characteristics of concrete using ring specimens. Materials Journal, 100, 239-245.

Siddique, R., Khatib, J., \& Kaur, I. (2008). Use of recycled plastic in concrete: A review. Waste Management, 28, 1835-1852.

Sivakumar, A., \& Santhanam, M. (1995). Mechanical properties of high strength concrete reinforced with metallic and nonmetallic fibres. Cement and Concrete Composites, 29, 119-124.

Song, P. S., Hwang, S., \& Sheu, B. C. (2005). Strength properties of nylon- and polypropylenefiber- reinforced concretes. Cement and Concrete Research, 35, 1546-1550.

Thomas, M. (1996). Chloride thresholds in marine concrete. Cement and Concrete Research, 26(4), 513-519.

Turcry, P., Loukili, A., Haidar, K., Pijandier-Cabot, G., \& Belarbi, A. (2006). Cracking tendency of selfcompacting concrete subjected to restrained shrinkage: Experimental 
study and modeling. ASCE Journal of Materials in Civil Engineering, 18, 46-54.

UNI 79287. (1978). Concrete-determination of the ion chloride penetration. UNI-Ente Nazionale Italiano Di Unificazione, Milano, piazza A. Diaz, 2.
Zoorob, S. E., \& Suparma, L. B. (2000). Laboratory design and investigation of the properties of continuously graded asphaltic concrete containing recycled plastics aggregate replacement (Plastiphalt). Cement and Concrete Composites, 22, 233-242. 